\title{
Cancer and SARS-CoV-2 Infection: A Third-Level Hospital Experience
}

\author{
Virginia Calvo (1D) \\ Ana Fernandez-Cruz ${ }^{2}$ \\ Beatriz Nuñez' \\ Mariola Blanco' \\ Ana Morito' \\ Marta Martínez' \\ Cristina Traseira' \\ Yago Garitaonaindía' \\ Ramon Aguado' \\ Arturo Ramos ${ }^{3}$ \\ Ana Royuela ${ }^{4}$ \\ Fernando Fabio Franco' \\ Mariano Provencio (D) \\ 'Medical Oncology Department, Hospital \\ Universitario Puerta de Hierro, Madrid, \\ Spain; ${ }^{2}$ Internal Medicine Department, \\ Hospital Universitario Puerta de Hierro, \\ Madrid, Spain; ${ }^{3}$ Admission, Hospital \\ Universitario Puerta de Hierro, Madrid, \\ Spain; ${ }^{4}$ Statistics-CIBERESP, Hospital \\ Universitario Puerta de Hierro, Madrid, \\ Spain
}

Correspondence: Mariano Provencio; Virginia Calvo

Medical Oncology Department, Hospital Universitario Puerta de Hierro,

Majadahonda, Manuel de Falla I, Majadahonda, Madrid, 28222, Spain

Tel +349II $916000 ;+349$ II 916279

Email mprovenciop@gmail.com;

vircalvo@hotmail.com
Introduction: Madrid has been the epicenter of the severe acute respiratory syndrome coronavirus 2 (SARS-CoV-2) pandemic in Spain. We analyzed our experience with SARSCoV-2 infected and cancer patients.

Patients and Methods: We included patients from March 1 to April 302020 at Hospital Universitario Puerta de Hierro, Majadahonda, Madrid (Spain). The inclusion criteria were diagnosis of SARS-CoV-2 infection made by reverse transcription polymerase chain reaction (RT-PCR) of nasopharyngeal specimens in cancer patients who were admitted to the hospital due to the need for respiratory support. The exclusion criteria were suspected cases not confirmed. The primary objective was to analyze the mortality rates of patients with cancer, especially those with lung cancer and COVID-19.

Results: Overall in-hospital mortality of cancer patients with coronavirus disease 2019 (COVID-19) was $15.2 \%$ similar to $12.7 \%$ of the global COVID-19 hospitalized population $(\mathrm{p}=0.615)$ and greater than that of patients admitted without SARS-CoV-2 infection during the same period $4.3 \%(\mathrm{p}<0.001)$. Among 653 patients receiving active cancer therapy during the study period, 24 (3.7\%) developed COVID-19 and required admission, $4.2 \%$ of those receiving chemotherapy, $9.5 \%$ immunotherapy and $2.1 \%$ targeted therapies. Lung and breast cancer were the most frequent cancer types (26.1\%), followed by colorectal cancer $(19.6 \%)$. Mortality in patients with lung cancer was $25 \%$. The univariate analysis comparing patients who developed a serious event to those who did not showed that the higher Brescia index, CURB-65 scale, lactate dehydrogenase (LDH) or C-reactive protein (CRP) were the risk factors of developing severe complications.

Conclusion: Patients with cancer, especially lung cancer, and SARS-CoV-2 infection have a worse overall prognosis than the general population.

Keywords: cancer, COVID-19, lung cancer, severe clinical events

\section{Introduction}

Coronavirus disease 2019 (COVID-19) has led to an unprecedented pandemic situation all over the world; since it appeared in Wuhan, China, in December $2019,{ }^{1,2}$ more than 2.5 million deaths have been reported. In the present moment, 124,871,140 severe acute respiratory syndrome coronavirus 2 (SARS-CoV-2) infections have been confirmed worldwide. Epidemiological data indicate that patients have a higher morbidity and mortality if they have at least one of the following characteristics: being older than 65 years old, or having either hypertension, cardiovascular disease, diabetes, chronic respiratory disease, renal disease, obesity or cancer. ${ }^{3-5}$

There are few studies with small cohorts describing cancer and COVID-19. Liang et $\mathrm{al}^{6}$ on a Chinese cohort describe a higher incidence than expected 
$(0.29 \%)$ of patients with cancer history, with $18(1 \%$, 95\% CI: $0.61-1.65)$ out of 1590 cases with COVID-19, having 5 of them (28\%) lung cancer. Information about treatment was available for 16 patients. Four have received chemotherapy or surgery in the previous month and 12 developed SARS-CoV-2 during their follow-up after surgery resection, these 4 patients had a higher risk of severe events describing the older age as a risk factor (OR 1.43, 95\% CI: 0.97-2.12; $\mathrm{p}=0.072$ ). Even though it is difficult to obtain any conclusion with a small cohort of patients, other studies ${ }^{7,8}$ have supported the lack of information and the vulnerability of cancer patients according to age, gender and comorbidities as COVID-19 related deaths.

Madrid has been the epicenter of the SARS-CoV-2 pandemic in Spain. We analyzed our experience with SARS-CoV-2 infected and cancer patients during the period of highest incidence of the first wave.

\section{Patients and Methods}

We analyzed our experience with SARS-CoV-2 infected and cancer patients from March 1, 2020, to April 30, 2020 at the Hospital Universitario Puerta de Hierro of Madrid (Spain). This was the period of most incidence of the first wave of the pandemic in Madrid.

The inclusion criteria were diagnosis of SARS-CoV-2 infection made by reverse transcription polymerase chain reaction (RT-PCR) of nasopharyngeal specimens in cancer patients who were admitted to the hospital due to the need for respiratory support. The exclusion criteria were suspected cases not confirmed.

The primary objective was to analyze the mortality rates of patients with cancer, especially those with lung cancer and COVID-19.

Acute respiratory distress syndrome (ARDS) was defined according to the interim guidance from the World Health Organization (WHO) for COVID-19. ${ }^{9}$

Clinical features and disease evolution have been described, focusing on the development of severe events during their admission. Severe event was defined as having severe respiratory distress, the need for mechanical ventilation, admission to an intensive care unit (ICU) or death. All information related to demographics features, patient comorbidities, medical history, laboratory tests, treatments received in the 30 days prior to admission, as well as all the tumor and oncological information, has also been collected.

\section{Statistical Analysis}

Descriptive analysis has been performed by means of absolute and relative frequencies for categorical variables and mean (standard deviation), or median (percentiles 25 and 75) for numerical variables. Univariable analysis was made with the chi-square or Fisher's exact tests for categorical variables and Mann-Whitney test for numerical. Significance level was established at 0.05. The software used was Stata/IC v.16. (StataCorp. 2019. Stata Statistical Software: Release 16. College Station, TX: StataCorp LLC).

\section{Ethics Approval}

The study was evaluated by the Ethical Committee of Hospital Universitario Puerta de Hierro de Majadahonda, Madrid.

Our Institutional Ethics Review Board approved the study and waived the need for informed consent due to the characteristics of the study.

The study was carried out following the Declaration of Helsinki on Good Clinical Practices and Organic Law 3/ 2018, 5th December on Protection of Personal Data and digital rights that were guaranteed during the study.

\section{Results}

From March 1, 2020, to April 30, 2020, overall in-hospital mortality of cancer patients with COVID-19 was $15.2 \%$ (95\% CI, 6.3; 5.2) (7/46).

Patients with COVID-19 and cancer had an average age of 65 years in men and 60 years in women, although the average age of the deceased was 68 and 63 years respectively.

Mortality in men was $12 \%$ in COVID-19 without cancer, $17 \%$ with COVID-19 and cancer and 5\% without COVID-19 either cancer, while in women it was $13 \%$, $15 \%$ and $4 \%$ respectively.

Table 1 shows the general characteristics of our series. Risk factors for COVID-19, such as hypertension or dyslipidemia, were prevalent among cancer patients.

After consulting the included patients, we know that a high proportion of cancer patients acquired their SARSCoV-2 infection due to their contact with healthcare system (30.4\% health-care related and 6.6\% hospital-acquired).

Among the 653 patients who received active cancer therapy during the study period, 3.7\% (24/653) developed COVID-19 and required admission, 4.2\% (16/378) of those who received chemotherapy, 9.5\% (6/63) of those receiving immunotherapy and $2.1 \%(2 / 97)$ of those treated 
Table I General Characteristics of the Series

\begin{tabular}{|c|c|c|}
\hline Variables & $\begin{array}{c}\text { Other Cancer } \\
\text { Patients, N=34 } \\
\text { (\%) }\end{array}$ & $\begin{array}{c}\text { Lung Cancer } \\
\text { Patients, } \mathrm{N}=12 \\
\text { (\%) }\end{array}$ \\
\hline Gender (male) & $18(52.9)$ & $6(50.0)$ \\
\hline $\begin{array}{l}\text { Age at hospitalization, } \\
\text { years, mean }(S D)\end{array}$ & $63.9(10.2)$ & $63.5(15.5)$ \\
\hline Active Smoking & $0(0.0)$ & $2(16.7)$ \\
\hline Ex-smokers & $12(35.3)$ & $6(50.0)$ \\
\hline $\begin{array}{l}\text { Comorbidities } \\
\text { Coronary heart } \\
\text { disease } \\
\text { Hypertension } \\
\text { Hypothyroidism } \\
\text { COPD* } \\
\text { Obesity } \\
\text { Diabetes } \\
\text { Dyslipidemia }\end{array}$ & $\begin{array}{c}3(8.8) \\
12(35.3) \\
3(8.8) \\
3(8.8) \\
2(5.9) \\
6(17.7) \\
8(23.5)\end{array}$ & $\begin{array}{l}2(16.7) \\
5(4 \mid .7) \\
0(0.0) \\
2(16.7) \\
0(0.0) \\
0(0.0) \\
3(25.0)\end{array}$ \\
\hline $\begin{array}{l}\text { Stage } \\
\text { I } \\
\text { II } \\
\text { III } \\
\text { IV }\end{array}$ & $\begin{array}{c}6(17.7) \\
5(14.7) \\
5(14.7) \\
18(52.9)\end{array}$ & $\begin{array}{l}0(0.0) \\
0(0.0) \\
6(50.0) \\
6(50.0)\end{array}$ \\
\hline $\begin{array}{l}\text { Lines of treatment } \\
\text { First line } \\
\text { Other lines } \\
\text { Pending treatment }\end{array}$ & $\begin{array}{l}18(52.9) \\
8(23.5) \\
8(23.5)\end{array}$ & $\begin{array}{l}5(4 I .7) \\
5(4 I .7) \\
2(16.7)\end{array}$ \\
\hline $\begin{array}{l}\text { Recent cancer } \\
\text { treatment }<30 \mathrm{~d} \\
\text { Active treatment }\end{array}$ & $\begin{array}{l}\text { II (32.3) } \\
23(67.6)\end{array}$ & $\begin{array}{l}8(66.7) \\
6(50.0)\end{array}$ \\
\hline $\begin{array}{l}\text { Last oncologic } \\
\text { treatment } \\
\text { Chemotherapy } \\
\text { Immunotherapy } \\
\text { Radiotherapy } \\
\text { Surgery } \\
\text { Others }\end{array}$ & $\begin{array}{c}14(42.4) \\
1(3.0) \\
3(9.1) \\
5(15.2) \\
10(30.3)\end{array}$ & $\begin{array}{c}2(20.0) \\
5(50.0) \\
0(0.0) \\
3(30.0) \\
0(0.0)\end{array}$ \\
\hline $\begin{array}{l}\text { Oncological } \\
\text { situation } \\
\text { Complete } \\
\text { response } \\
\text { Partial response } \\
\text { Stable disease } \\
\text { Progression } \\
\text { Best supportive } \\
\text { care } \\
\text { Others }\end{array}$ & $\begin{array}{l}17(50.0) \\
1(2.9) \\
1(2.9) \\
10(29.4) \\
2(5.9) \\
3(8.8)\end{array}$ & $\begin{array}{l}3(25.0) \\
4(33.3) \\
2(16.7) \\
\text { I (8.3) } \\
\text { I (8.3) } \\
\text { I (8.3) }\end{array}$ \\
\hline
\end{tabular}

Abbreviation: *COPD, chronic obstructive pulmonary disease. with targeted therapies. The remaining cancer patients admitted with COVID-19 were receiving palliative care $(6.6 \%)$ or were in complete response $(43.5 \%)$.

Lung and breast cancer were the most frequent cancer types $(26.1 \%)$, followed by colorectal cancer (19.6\%). More than a half (52\%) were stage IV. Although 19 $(41.3 \%)$ had received cancer therapy during the last 30 days, only 2 (4.6\%) had neutropenia below 1000 neutrophils/mL at COVID-19 presentation, and none of them received granulocyte colony-stimulating factor (G-CSF).

Of the 7 cancer patients who died from the infection, 3 patients had lung cancer and 4 patients other types of cancer.

Table 2 shows the main symptoms developed by the oncological patients as a result of the SARS-CoV-2, and the radiological and analytical findings that determine the prognosis. ARDS developed in 21.7\%; however, only 1 case required noninvasive mechanical ventilation (NIMV) and $2(4.3 \%)$ were admitted to ICU and required mechanical ventilation. None of our patients presented thrombotic events.

Different treatment options received during the SARSCoV-2 infection are presented in Table 3.

Table 4 presents the results of the univariate analysis comparing patients who developed a serious event to those who did not, according to baseline characteristics at admission. Each increase in the Brescia, the CURB-65 scale, elevated lactate dehydrogenase (LDH) and elevated C-reactive protein (CRP) on admission were statistically associated with developing a serious event.

Other variables such as age, sex, type of cancer, recent therapy or active therapy were not independent predictors of serious events in the present study.

The median time from admission to discharge was 7 days (P25; P75: 4; 14 days) and 3 days from admission to death.

\section{Discussion}

In our series, the mortality among SARS-CoV-2 infected patients with or without cancer was not significantly different, overall in-hospital mortality of cancer patients with COVID-19 was $15.2 \%$ (95\% CI, 6.3; 5.2) (7/46), similar to $12.7 \%(95 \% \mathrm{CI}, 11.1 ; 4.4)(216 / 1700)$ of the global COVID-19 hospitalized population and greater than that of patients admitted without SARS-CoV-2 infection during the same period $4.3 \%$ (95\% CI; 3.6; 5.2) (108/2520). 
Table 2 Symptoms at Diagnosis and Prognostic Data

\begin{tabular}{|c|c|c|c|}
\hline Symptoms & $\begin{array}{l}\text { Other Cancer Patients } \\
\qquad(\mathrm{N}=34)\end{array}$ & $\begin{array}{l}\text { Lung Cancer Patients } \\
\qquad(\mathrm{N}=12)\end{array}$ & P-value \\
\hline Neutropenia & $2(6.1)$ & $0(0.0)$ & 1.000 \\
\hline Cough & $23(67.6)$ & $5(4 \mid .7)$ & 0.170 \\
\hline Fever & $26(76.5)$ & $9(75.0)$ & 0.918 \\
\hline Temperature & $37.1(1.0)$ & $37.3(1.1)$ & 0.360 \\
\hline Dyspnea & $16(47.0)$ & II (9I.7) & 0.007 \\
\hline Diarrhea & $3(8.8)$ & I (8.3) & 1.000 \\
\hline Lymphopenia & $22(68.7)$ & $4(36.4)$ & 0.080 \\
\hline Alteration liver function & $3(9.4)$ & $2(18.2)$ & 0.589 \\
\hline Alteration kidney function & $4(12.5)$ & $2(18.2)$ & 0.637 \\
\hline $\begin{array}{l}\text { Radiological characteristics } \\
\text { Bilateral pneumonia } \\
\text { Unilateral pneumonia } \\
\text { Normal }\end{array}$ & $\begin{array}{c}23(71.9) \\
6(18.7) \\
3(9.4)\end{array}$ & $\begin{array}{c}8(72.7) \\
3(27.3) \\
0(0.0)\end{array}$ & 0.726 \\
\hline \multicolumn{4}{|l|}{ Prognostic criteria } \\
\hline $\begin{array}{l}\text { IL6 } \\
\qquad 44.4 \mathrm{pg} / \mathrm{mL} \\
\quad \geq 4.4 \mathrm{pg} / \mathrm{mL}\end{array}$ & $\begin{array}{c}28(82.3) \\
6(17.7)\end{array}$ & $\begin{array}{l}8(66.7) \\
4(33.3)\end{array}$ & 0.416 \\
\hline $\begin{array}{l}\text { D-DIMER } \\
<0.5 \mathrm{ng} / \mathrm{mL} \\
0.5-7 \mathrm{ng} / \mathrm{mL} \\
>7 \mathrm{ng} / \mathrm{mL}\end{array}$ & $\begin{array}{c}0.9(0.6 ; 2.2) \\
5(17.9) \\
22(78.6) \\
I(3.5)\end{array}$ & $\begin{array}{c}0.9(0.5 ; 2.7) \\
3(27.3) \\
8(72.7) \\
0(0.0)\end{array}$ & $\begin{array}{l}0.574 \\
0.761\end{array}$ \\
\hline $\begin{array}{l}\text { CRP } \\
\qquad 10 \mathrm{mg} / \mathrm{L} \\
10-150 \mathrm{mg} / \mathrm{L} \\
>150 \mathrm{mg} / \mathrm{L}\end{array}$ & $\begin{array}{l}7(21.9) \\
16(50.0) \\
9(28.1)\end{array}$ & $\begin{array}{l}107.7 \\
1(9.1) \\
8(72.7) \\
2(18.2)\end{array}$ & 0.449 \\
\hline $\begin{array}{l}\text { LDH } \\
\qquad 246 \mathrm{U} / \mathrm{L} \\
\quad \geq 246 \mathrm{U} / \mathrm{L}\end{array}$ & $\begin{array}{c}266(207 ; 326) \\
14(46.7) \\
16(53.3)\end{array}$ & $\begin{array}{c}290(238 ; 352) \\
3(27.3) \\
8(72.7)\end{array}$ & $\begin{array}{l}0.195 \\
0.309\end{array}$ \\
\hline Ferritin & $562(358 ; 933)$ & IIII (392; 2672) & 0.158 \\
\hline Charlson index* & $8(6 ; 9)$ & $8(6 ; 9)$ & 0.800 \\
\hline $\begin{array}{l}\text { CURB-65 scale** } \\
0-1 \\
\geq 2\end{array}$ & $\begin{array}{l}21(61.8) \\
13(38.2)\end{array}$ & $\begin{array}{l}5(4 \mid .7) \\
7(58.3)\end{array}$ & 0.314 \\
\hline $\begin{array}{l}\text { Brescia scale*** } \\
\quad 0-1 \\
\geq 2\end{array}$ & $\begin{array}{l}30(88.2) \\
4(11.8)\end{array}$ & $\begin{array}{l}8(66.7) \\
4(33.3)\end{array}$ & 0.178 \\
\hline
\end{tabular}

Notes: *Charlson index (Comorbidities index), ${ }^{* *}$ CURB-65 scale (includes age, confusion, urea, breathing frequency, blood pressure), Brescia scale*** (depends on oxygen needs). P-values correspond to comparison between lung cancer patients and the other types of cancer.

Abbreviations: CRP, C-reactive protein; $\mathrm{LDH}$, lactate dehydrogenase. 
Table 3 Treatment Received During the COVID-19

\begin{tabular}{|l|c|c|c|}
\hline Treatments & $\begin{array}{c}\text { Other Cancer Patients } \\
\mathbf{( N = 3 4 )}\end{array}$ & $\begin{array}{c}\text { Lung Cancer Patients } \\
\mathbf{( N = 1 2 )}\end{array}$ & p-value \\
\hline Hydroxychloroquine & $31(91.2)$ & II (100) & 0.565 \\
\hline Lopinavir/ritonavir & $18(52.9)$ & $6(54.5)$ & 1.000 \\
\hline Interferon & $3(8.8)$ & $3(27.3)$ & 0.146 \\
\hline Systemic Corticosteroids & $12(35.3)$ & $6(54.5)$ & 0.304 \\
\hline Tocilizumab & $2(5.9)$ & $1(9.1)$ & 1.000 \\
\hline Anakinra & $1(2.9)$ & $1(8.33)$ & 0.458 \\
\hline
\end{tabular}

Table 4 Univariate Analysis Comparing Patients with Serious Event vs Non-Serious Event

\begin{tabular}{|c|c|c|c|c|c|}
\hline Variable & $\mathbf{N}$ Valid $(\mathrm{N}=46)$ & Non Serious Event $(\mathbf{N}=\mathbf{3 8})$ & Serious Event $(\mathbf{N}=\mathbf{8})$ & p-value & OR (95\% CI) \\
\hline Gender (male) & 46 & $20(52.6)$ & $4(50.0)$ & 0.892 & $0.9(0.19 ; 4.14)$ \\
\hline Age at hospitalization (years) & 40 & $63.2(11.6)$ & $67(11.4)$ & 0.376 & $1.04(0.96 ; 1.21)$ \\
\hline Active Smoking & 46 & $2(5.3)$ & $0(0.0)$ & I & - \\
\hline Ex-smokers & 46 & $16(42.1)$ & $2(25.0)$ & 0.453 & $0.46(0.08 ; 2.57)$ \\
\hline Heart disease & 46 & $4(10.5)$ & $I(12.5)$ & $0.87 I$ & $1.21(0.12 ; 15.57)$ \\
\hline Hypertension & 46 & $14(36.8)$ & $3(37.5)$ & 0.972 & $1.02(0.21 ; 4.97)$ \\
\hline Hypothyroidism & 46 & $3(7.9)$ & $0(0.0)$ & I & - \\
\hline COPD* & 46 & $4(10.5)$ & $I(I 2.5)$ & $0.87 I$ & $1.21(0.12 ; 12.57)$ \\
\hline Obesity & 46 & $2(5.3)$ & $0(0.0)$ & I & - \\
\hline Diabetes & 46 & $6(15.8)$ & 0 & $0.57 I$ & - \\
\hline Dyslipidemia & 46 & $10(26.3)$ & I (I2.5) & 0.418 & $0.40(0.04 ; 3.67)$ \\
\hline First ferritin & 27 & $562(377 ; 1111)$ & $903(6 \mid 4 ; 1130)$ & 0.757 & $1.00(0.99 ; 1.00)$ \\
\hline Higher ferritin & 26 & $598(382 ; 1111)$ & $975(903 ; 2403)$ & 0.396 & $1.00(0.99 ; 1.00)$ \\
\hline First IL6 $\geq 4.4 \mathrm{pg} / \mathrm{mL}$ & 46 & $7(18.4)$ & $3(37.5)$ & 0.246 & $2.6(0.5 I ; 13.83)$ \\
\hline Higher IL6 $\geq 4.4 \mathrm{pg} / \mathrm{mL}$ & 46 & $8(21.1)$ & $3(37.5)$ & 0.330 & $2.2(0.44 ; 11.48)$ \\
\hline First D-Dimer & 39 & $0.8(0.6 ; 1.9)$ & I.7 (0.6; 2.7) & 0.133 & $1.38(0.90 ; 2.11)$ \\
\hline Higher D-Dimer & 41 & I.I $(0.7 ; 2.2)$ & $2.6(1.5 ; 5.6)$ & 0.069 & $1.39(0.97 ; 1.99)$ \\
\hline First $\mathrm{LDH}^{* *}$ & 41 & $254(195 ; 316)$ & $354(266 ; 44 I)$ & 0.020 & $1.01(1.00 ; 1.03)$ \\
\hline Higher LDH & 40 & $27 \mathrm{I}(227 ; 332)$ & $619(354 ; 812)$ & 0.007 & $1.01(1.00 ; 1.03)$ \\
\hline First CRP**** & 43 & $95(11 ; 146)$ & $169(89 ; 228)$ & 0.038 & $1.01(1.00 ; 1.02)$ \\
\hline Higher CRP & 42 & $116(43 ; 167)$ & $202(130 ; 249)$ & 0.018 & $1.02(1.00 ; 1.03)$ \\
\hline Brescia & 44 & $0.5(0 ; 1)$ & $2(2 ; 5)$ & 0.004 & $19.5(2.54 ; 149.7)$ \\
\hline CURB-65 & 42 & $I(I ; 2)$ & $2(1 ; 3)$ & 0.060 & $2.4 \mathrm{I}(0.97 ; 6.03)$ \\
\hline
\end{tabular}

Abbreviations: *COPD, chronic obstructive pulmonary disease; **LDH, lactate dehydrogenase; ***CRP, C-Reactive protein. 
No association was found between the oncological treatment and the development of a serious event linked SARS$\mathrm{CoV}-2$ infection. Nor were any objective analytical data easily identifiable in the clinic observed. In our opinion, the management of cancer patients with SARS-CoV-2 infection should not differ from those who do not have cancer.

The higher mortality in men compared to women and the apparent greater tendency to admission among patients undergoing immunotherapy remain to be investigated, but the small sample size does not allow more than hypothesis. In two independent cohorts of patients with heart failure, plasma concentrations of angiotensin-converting enzyme 2 (ACE2) were higher in men than in women, and these data might explain the higher incidence and fatality rate of COVID-19 in men. ${ }^{10}$

No significant differences have been found between lung cancer patients with SARS-CoV-2 infection admitted with the rest of the cancer patients and SARS-CoV-2 infection in any of the parameters studied, or in the treatments received. However, the highest mortality rate has been in patients with lung cancer, although no differences were found in the objective data at admission.

No clear association has been found between the severity of the infection and the specific cancer treatment received, paying special attention to immunotherapy. Other authors also do not find that immunotherapy has a clear impact on the severity of the infection. ${ }^{11}$

Our mortality rate in patients with lung cancer $(25 \%)$ is similar to what has been reported by the Memorial Sloan group in New York, which is $24 \%$, with similar treatments for infection, even in ICU access. The mortality, in patients with thoracic cancer, reported in the Thoracic Cancers International COVID-19 Collaboration (TERAVOLT) registry, was 33\%. ${ }^{12}$ We know the role of Neuropilin-1 (NRP1), a member of a family of signaling proteins that facilitates SARS-CoV-2 cell entry and provides a possible pathway into the central nervous system. NRP1 is abundantly expressed in the respiratory and olfactory epithelium. NRP1 is highly expressed in lung cancer compared with normal lung. ${ }^{13}$ NRP1 is a cancer invasion and angiogenesis enhancer. NRP1 expression is an independent predictor of cancer relapse and poor survival in NSCLC patients. ${ }^{14}$

Even though it is difficult to have any conclusion with a small cohort of patients, other studies have supported the lack of information and the vulnerability of cancer patients in China ${ }^{7}$ as well as in Europe, ${ }^{15}$ including age, gender and comorbidities as COVID-19 related deaths. However, larger studies on cancer patients and SARS-COV-2 infected patients have demonstrated that cancer types, cancer stage and cancer treatment contribute to severe event development. ${ }^{16}$

Our series has a clear selection bias since only patients with confirmed infection by PCR and who were admitted to the hospital due to the need for respiratory support and a serious situation have been studied. Those SARS-CoV-2 infected patients without admission are not represented, so the selection is among those with the worst prognosis. Mortality could not be higher since all cancer patients at the center have access to treatment and hospitalization without any limitation, beyond the medical one.

We could suspect COVID-19 if leukopenia or lymphopenia are present, as well as elevated transaminases, CRP, d-dimer, ferritin and LDH. ${ }^{17}$ In addition, an increase in interleukin 6 could be observed during the cytokine storm and could be considered a systemic disease indicator, including renal or cardiogenic failure. ${ }^{18}$

In our series, both the Brescia index and LDH, CPR, and to a lesser extent, CURB-65 are associated with a worse prognosis and a greater possibility of developing serious events. We believe that these clinical and analytical alterations have a greater prognostic value for a torpid evolution than the location of the tumor, taking into account that some of the symptoms may be associated with lung cancer and they force us to make a differential diagnosis with it. ${ }^{19}$

Other symptoms that do not normally appear in lung cancer patients could be helpful, as diarrhea, that appeared in a small percentage of our patients, or other digestive symptoms, such as headache, anosmia or ageusia, among others. ${ }^{20}$

Reviewing the bibliography, we question the recommendation about using prophylactic G-CSF in some guidelines when, for example, pembrolizumab plus chemotherapy has around $5 \%$ of febrile neutropenia ${ }^{21}$ and no febrile neutropenia has been found among our patients.

On the contrary and according to the results obtained in our series, those patients with high LDH or CRP levels, high Brescia or CURB-65 should be considered as a population with a high risk of death or serious event in cancer patients and should be evaluated early for ICU admission.

\section{Conclusions}

Patients with cancer, especially lung cancer, and SARS-CoV-2 infection have a worse overall prognosis than the general population. Objective parameters such as LDH, CRP at admission, Brescia index or CURB-65 should alert us to a more 
serious evolution and suggest an early admission to the intensive care unit.

\section{Ethics Approval}

The study was evaluated by the Ethical Committee of Hospital Universitario Puerta de Hierro de Majadahonda, Madrid.

Our Institutional Ethics Review Board approved the study and waived the need for informed consent.

The study was carried out following the Declaration of Helsinki on Good Clinical Practices and Organic Law 3/ 2018, 5th December on Protection of Personal Data and digital rights that were guaranteed during the study.

\section{Acknowledgments}

This paper is part of a project that has received funding from the European Union's Horizon 2020 research and innovation program under grant agreement No 875160 .

\section{Author Contributions}

All authors made substantial contributions to the conception or design of the work and the acquisition, analysis and interpretation of data; drafted the work and revised it critically for important intellectual content; approved the version to be published; and agree to be accountable for all aspects of the work in ensuring that questions related to the accuracy or integrity of any part of the work are appropriately investigated and resolved.

\section{Disclosure}

Dr. Provencio has received personal fees from BristolMyers Squibb (BMS), Merck Sharp \& Dohme (MSD), Roche, AstraZeneca and Takeda.

Dr. Calvo has received personal fees from Bristol-Myers Squibb (BMS), Merck Sharp \& Dohme (MSD), Roche, AstraZeneca and Takeda.

The other authors have no conflicts of interest to declare.

\section{References}

1. Liu J, Zhang S, Wu Z, et al. Clinical outcomes of COVID-19 in Wuhan, China: a large cohort study. Ann Intensive Care. 2020;10 (1):99. doi:10.1186/s13613-020-00706-3.

2. Guan W-J, Ni Z-Y, Hu Y, et al. Clinical characteristics of coronavirus disease 2019 in China. $N$ Engl $J$ Med. 2020;382(18):1708-1720. doi:10.1056/NEJMoa2002032.

3. Richardson S, Hirsch JS, Narasimhan M, et al. Presenting characteristics, comorbidities, and outcomes among 5700 patients hospitalized with COVID-19 in the New York city area. JAMA. 2020;323(20): e206775. doi:10.1001/jama.2020.6775.
4. Myers LC, Parodi SM, Escobar GJ, Liu VX. Characteristics of hospitalized adults with COVID-19 in an integrated health care system in California. JAMA. 2020;323(21):e207202. doi:10.1001/ jama.2020.7202.

5. Xu Z, Shi L, Wang Y, et al. Pathological findings of COVID-19 associated with acute respiratory distress syndrome. Lancet Respir Med. 2020;8(4):420-422. doi:10.1016/S2213-2600(20)30076-X.

6. Liang W, Guan W, Chen R, et al. Cancer patients in SARS-CoV-2 infection: a nationwide analysis in China. Lancet Oncol. 2020;21 (3):335-337. doi:10.1016/S1470-2045(20)30096-6.

7. Yu J, Ouyang W, Chua MLK, Xie C. SARS-CoV-2 transmission in patients with cancer at a Tertiary Care Hospital in Wuhan, China. JAMA Oncol. 2020;e200980. doi:10.1001/jamaoncol.2020.0980.

8. Zhang L, Zhu F, Xie L, et al. Clinical characteristics of COVID-19infected cancer patients: a retrospective case study in three hospitals within Wuhan, China. Ann Oncol. 2020:S0923-7534(20)36383-3. doi:10.1016/j.annonc.2020.03.296.

9. World Health Organization (WHO). Clinical Management of Severe Acute Respiratory Infection when novel coronavirus (nCoV) infection is suspected. Interim Guidance. Geneva: World Health Organization; 2020.

10. Sama IE, Ravera A, Santema BT, et al. Circulating plasma concentrations of angiotensin-converting enzyme 2 in men and women with heart failure and effects of renin-angiotensin-aldosterone inhibitors. Eur Heart J. 2020;41(19):1810-1817. doi:10.1093/eurheartj/ehaa373.

11. Luo J, Rizvi EJV, Preeshagul IR, Wolchok JD, Hellmann MD. Impact of PD-1 blockade on severity of COVID-19 in patients with lung cancers. Cancer Discov. 2020:CD-20-0596. doi:10.1158/2159-8290.CD-20-0596.

12. Garassino MC, Whisenant JG, Huang L-C, et al. COVID-19 in patients with thoracic malignancies (TERAVOLT) first results of an international, registry-based, cohort study. Lancet Oncol. 2020;21:914-922. doi:10.1016/S1470-2045(20)30314-4.

13. El-Arabey AA, Abdalla M. Transplacental transmission of SARS-CoV-2 infection via NRP1. Travel Med Infect Dis. 2021;40:101987. doi:10.1016/j.tmaid.2021.101987.

14. Hong T-M, Chen Y-L, Wu -Y-Y, et al. Targeting neuropilin 1 as an antitumor strategy in lung cancer. Clin Cancer Res. 2007;13:4759-4768. doi:10.1158/1078-0432.CCR-07-0001.

15. Onder G, Rezza G, Brusaferro S. Case-fatality rate and characteristics of patients dying in relation to COVID-19 in Italy. JAMA. 2020. doi:10.1001/jama.2020.4683.

16. Dai M, Liu D, Liu M, et al. Patients with cancer appear more vulnerable to SARS-CoV-2: a Multi-Center Study during the COVID-19 outbreak. Cancer Discov. 2020:CD-20-0422. doi:10.1158/2159-8290.CD-20-0422.

17. Zheng C, Wang J, Guo H, et al. Risk-adapted treatment strategy for COVID-19 patients. Int J Infect Dis. 2020;94:74-77. doi:10.1016/j. ijid.2020.03.047.

18. Chen N, Zhou M, Dong X, et al. Epidemiological and clinical characteristics of 99 cases of 2019 novel coronavirus pneumonia in Wuhan, China: a descriptive study. Lancet. 2020;395 (10223):507-513. doi:10.1016/S0140-6736(20)30211-7.

19. Provencio M, Carcereny E, Rodríguez-Abreu D, et al. Lung cancer in Spain: information from the Thoracic Tumors Registry (TTR Study). Trans Lung Cancer Res. 2019;8(4):461-475. doi:10.21037/ tlcr.2019.08.05.

20. Mao L, Jin H, Wang M, et al. Neurologic manifestations of hospitalized patients with Coronavirus Disease 2019 in Wuhan, China. JAMA Neurol. 2020;77(6):e201127. doi:10.1001/jamaneuro 1.2020 .1127$.

21. Paz-Ares L, Luft A, Vicente D, et al. Pembrolizumab plus chemotherapy for squamous non-small-cell lung cancer. $N$ Engl $J$ Med. 2018;379:2040-2051. doi:10.1056/NEJMoa1810865. 


\section{Publish your work in this journal}

Clinical Epidemiology is an international, peer-reviewed, open access, online journal focusing on disease and drug epidemiology, identification of risk factors and screening procedures to develop optimal preventative initiatives and programs. Specific topics include: diagnosis, prognosis, treatment, screening, prevention, risk factor modification,

Submit your manuscript here: https://www.dovepress.com/clinical-epidemiology-journal systematic reviews, risk \& safety of medical interventions, epidemiology \& biostatistical methods, and evaluation of guidelines, translational medicine, health policies \& economic evaluations. The manuscript management system is completely online and includes a very quick and fair peer-review system, which is all easy to use. 